\title{
A fresh look at kelp bed phytoplankton populations in an upwelling area
}

\author{
P. J. Fielding ${ }^{1}$, L. J. Seiderer ${ }^{2, *}$ \\ ${ }^{1}$ Oceanographic Research Institute, PO Box 10712, Marine Parade 4056, Durban, South Africa \\ ${ }^{2}$ Zoology Department, University of Cape Town, Rondebosch 7700, South Africa
}

\begin{abstract}
Algal pigment concentrations in the water column of a southern Benguela kelp bed were measured daily during summer and winter using High Performance Liquid Chromatography (HPLC) and spectrophotometric methods. Chlorophyll a concentrations estimated by HPLC were significantly lower than those estimated by the trichromatic equations of Jeffrey \& Humphrey (1975; Biochem. Physiol. Pflanz. 167: 191-194), although differences were relatively small. There was no significant difference between chlorophyll a concentrations estimated by HPLC and the spectrophotometric equation of Lorenzen (1967; Limnol. Oceanogr. 12: 243-246). Mean HPLC chlorophyll a concentrations were $1.64 \mathrm{\mu g} \mathrm{l}^{-1}$ in summer and $1.78 \mu \mathrm{gl}^{-1}$ in winter. Previous spectrophotometric estimates of kelp bed chlorophyll a concentrations were generally comparable to those determined by HPLC. In summer, $5 \mathrm{~d}$ pulses of southeasterly winds caused upwelling of cold nutrient-rich water into the kelp bed, which resulted in phytoplankton blooms. Time series analysis indicated that HPLC chlorophyll a concentrations were positively correlated with the upwelling index of $5 \mathrm{~d}$ previously, swell height of the same day and sea temperature of the previous day. In winter, winds were mainly northwesterly, sea temperatures were stable, and chlorophyll a concentrations were negatively correlated with swell height of $2 \mathrm{~d}$ previously. Phaeopigment concentrations determined by the method of Lorenzen (1967) reached $7.04 \mu \mathrm{g} \mathrm{l}^{-1}$ and were significantly higher than phaeophytin a concentrations determined by HPLC, which rarely exceeded $2 \mu \mathrm{gl}^{-1}$ Chlorophyllide a occured in $57 \%$ of summer samples and $43 \%$ of winter samples, and was more prevalent than phaeophytin $a$. Chlorophyllide $a$ and chlorophyll $a$ concentrations of the same day were significantly correlated in both summer and winter. Fucoxanthin concentrations reached $5.35 \mu \mathrm{g} \mathrm{l^{-1 }}$ in winter and $2.04 \mu \mathrm{g} \mathrm{l}^{-1}$ in summer, and daily winter fucoxanthin concentrations were highly correlated with chlorophyll a concentrations. Fucoxanthin and chlorophyll $c$, pigments characteristic of kelps and diatoms, occurred in $>90 \%$ of winter samples and in $<35 \%$ of summer samples. The kelp bed particulate resource in winter was therefore qualitatively different from the summer particulate resource.
\end{abstract}

\section{INTRODUCTION}

On the west coast of South Africa frequent pulses of upwelling, generated by strong southeasterly winds, result in the rapid escalation of nutrient concentrations in the inshore and offshore regions. Once upwelling relaxes or downwelling occurs, phytoplankton production increases very rapidly in response to the high nutrient levels (Andrews \& Hutchings 1980, Field et al. 1980, Carter 1982, Brown \& Field 1986). Phytoplankton thus represents a potential food source for filter feeders in the inshore region. It has been estimated that phytoplankton contributes ca $50 \%$ of the primary production in the inshore area (Newell et al. 1982). Estimates of

\footnotetext{
- Present address: Marine Ecological Surveys Ltd, 2 Chilecito Villas, Four St., Lelant, St Ives, Cornwall TR26 3EN, UK
}

chlorophyll concentrations as indicators of phytoplankton biomass in the vicinity of the kelp beds of South Africa have generally been made by spectrophotometric methods, using either SCOR-UNESCO (1966) or Strickland \& Parsons (1972) trichromatic equations. These methods may overestimate photosynthetically active pigment concentrations (Jacobsen 1978, 1982, Mantoura \& Llewellyn 1983, Daemen 1986).

Separation of algal pigments by High Performance Liquid Chromatography (HPLC) provides a method for accurate quantification of the various elements of the water column pigment matrix. HPLC has been used to analyse fluctuations in various components of the matrix as an indicator of physiological and structural changes in water column algal populations (Gieskes \& Kraay 1983, 1986a, b, Monteiro et al. 1986, Burkill et al. 1987. Klein \& Sournia 1987). Previous microscopic 
studies have indicated that the kelp bed phytoplankton population is dominated by diatoms (Field et al. 1980, Barlow 1982, Olivieri 1983, Brown \& Field 1985). However, many delicate algal cells may be destroyed by preservation in traditional fixatives (Gieskes \& Kraay 1983) and separation of photosynthetic pigments during diatom-dominated phytoplankton blooms has shown that other algal classes such as cryptomonads and green algae may play an important role in phytoplankton communities (Gieskes \& Kraay 1983, Klein \& Sournia 1987, Wright \& Jeffrey 1987). Using HPLC analyses of the chlorophyll-like pigments present during cyclical upwelling and downwelling events, the nature of changes in the growth and status of the phytoplankton population in the kelp bed system can be estimated.

The following work was carried out with 3 objectives: (1) to compare HPLC and spectrophotometric estimates of kelp bed chlorophyll a concentrations in order to assess whether previous values for chlorophyll a concentrations in the kelp bed area are overestimates; (2) to examine daily changes in the water column photosynthetic pigments with season and environmental variables, using time series analysis techniques; (3) to assess qualitative changes in the kelp bed water column pigment matrix as an indicator of the composition of the phytoplankton population.

\section{MATERIALS AND METHODS}

Sampling procedure: chlorophyll a. Water samples were collected daily at 08:00 h at $1 \mathrm{~m}$ depth from the rocky shore at Oudekraal, on the west coast of the Cape Peninsula, South Africa, for $52 \mathrm{~d}$ in November/ December 1984, which is the principal summer upwelling season (Andrews \& Hutchings 1980), and for $31 \mathrm{~d}$ in June/July 1985 (winter). Between 100 and $900 \mathrm{ml}$, depending on particulate load, was filtered by gentle hand pump filtration, in subdued light, first through a $200 \mu \mathrm{m}$ mesh and then through Whatman GF/F filters. Each sample was analysed for algal pigments by HPLC and for chlorophyll $a$ and phaeopigments by spectrophotometry. No magnesium carbonate wash was added to filters because it can bind chlorophyllides and phaeophytins (Daley et al. 1973). After filtration, filter papers were folded, wrapped in aluminium foil and stored in liquid nitrogen until analysed.

Sea temperature was measured at the time of sample collection and a visual estimate made of swell height. Average daily wind speed and direction at a height $10 \mathrm{~m}$ above the sea surface were obtained from Koeberg weather station about $10 \mathrm{~km}$ north of the sample site. The longshore wind component was calculated according to the upwelling index

$$
V t=U(\cos \theta-160)
$$

where $U=$ wind speed; $\theta=$ wind direction; and 160 is the orientation of the Cape west coast (Jury 1980). These were plotted on a scale of +10 to -10 where 0 represents the boundary between upwelling $(+)$ and downwelling $(-)$.

Extraction of pigments. Solvents for extraction and chromatography were all of Analar grade. Pigments were extracted using $90 \%$ acetone. Filters were ground in $2.5 \mathrm{ml} 90 \%$ acetone for $1 \mathrm{~min}$ with a motorized tissue grinder. The slurry was transferred to a centrifuge tube and centrifuged at $12000 \times g$ for $60 \mathrm{~s}$. Chlorophyll $a$ is converted to chlorophyllide a very rapidly, especially when samples contain a large proportion of diatoms (Jeffrey \& Hallegraeff 1987), so samples were extracted and analysed in the shortest possible time (ca $12 \mathrm{~min}$ ).

HPLC analysis. Exactly $300 \mu \mathrm{l}$ of the acetone extract was removed with a Hamilton syringe and mixed with $100 \mu \mathrm{l}$ of an ion-pairing reagent prepared from $1.5 \mathrm{~g}$ tetrabutyl-ammonium acetate and $7.7 \mathrm{~g}$ of ammonium acetate made up to $100 \mathrm{ml}$ with water (Mantoura \& Llewellyn 1983). The chromatographic separations were carried out using a Beckman HPLC system comprising 2 model 112 pumps and a 340 organiser, coupled to a Drew Scientific Chromatography Interface linked to an Apple IIC computer for both gradient control and peak integration. A Beckman model 165 variable wavelength detector was used with a wavelength setting of $440 \mathrm{~nm}$. A $100 \mu \mathrm{l}$ injection loop was used and separations were carried out using a $7 \mathrm{~cm}$ Altex XL ODS reverse phase column with $3 \mu \mathrm{m}$ packing. This column allowed the shortening of analysis time to $8.5 \mathrm{~min}$ without loss of resolution (Fig. 1), thus making the method suitable for large numbers of samples (Monteiro et al. 1986). The composition of the 2 mobile phase solvents was as described by Mantoura \& Llewellyn (1983), but the gradient profile was changed to suit the shorter column.

Peaks were identified by comparison with pigment standards (Monteiro 1986, Monteiro et al. 1986) and calibration for the quantification of chlorophyll $a$ and chlorophyllide a was carried out using a chlorophyll a standard (Sigma Chemical Company, Product code: C6144) made up to known volume in $90 \%$ acetone and stored at $-20^{\circ} \mathrm{C}$ in the dark (Mantoura \& Llewellyn 1983). The corresponding concentrations of breakdown products, xanthophylls and carotenoids were determined using the ratios of the molar extinction coefficients of chlorophyll $a$ and the known component of $\tau=440 \mathrm{~nm}$ (Monteiro et al. 1986). Chlorophyll $b_{1}$ chlorophyll $c$, lutein and phaephorbide a were not quantitatively analysed but simply described as present or absent in the chromatograms. 
Spectrophotometric analysis. Exactly $1.6 \mathrm{ml}$ of each extract analysed by HPLC was transferred to a $1 \mathrm{~cm}$ pathlength cuvette and read at $750,665,664,647$ and $630 \mathrm{~nm}$ in a Beckman model 25 spectrophotometer. Thereafter, $25 \mu \mathrm{l}$ of $0.2 \mathrm{M} \mathrm{HCl}$ was added to achieve a final concentration of $3 \times 10^{-3} \mathrm{M} \mathrm{HCl}$, so reducing spectral changes caused by acidification (Holm-

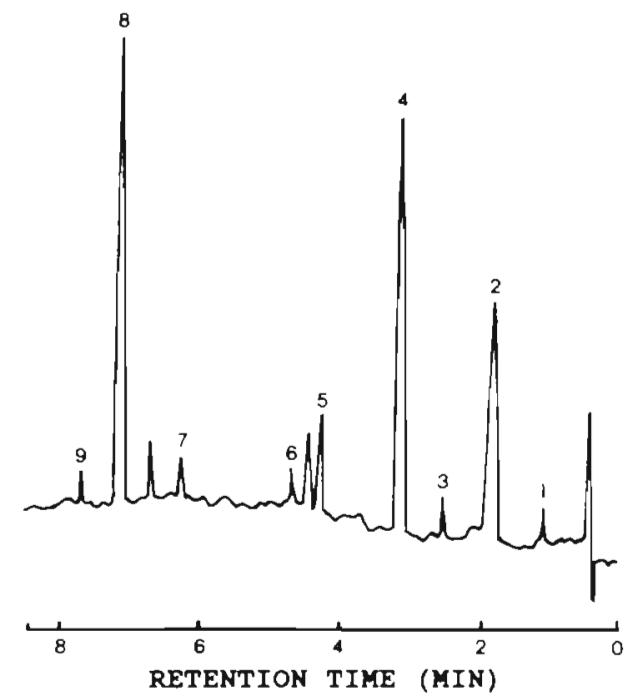

Fig. 1. Chromatogram of the absorbance of the pigment extract from the sample on 15 July 1985. Pigments: 1, chlorophyllide $a_{;}$2, chlorophyll $c ; 3$, phaeophorbide; 4, fucoxanthin; 5, diadinoxanthin; 6 , diatoxanthin; 7 , chlorophyll $b_{i}$ 8 , chlorophyll $a ; 9$, phaeophytin a
Hansen 1978, Rieman 1978). The cuvette was inverted twice and allowed to stand for $1 \mathrm{~min}$ before readings were taken at 750 and $665 \mathrm{~nm}$.

Comparison of pigment concentrations. Chlorophyll $a$ and phaeophytin a concentrations of the samples analysed by HPLC were compared with concentrations calculated spectrophotometrically using the Jeffrey \& Humphrey (1975) trichromatic equations (chlorophyll a only) and the Lorenzen (1967) equations for chlorophyll $a$ and phaeopigments, using a paired $t$-test (Statpro, Wadsworths). Time series analyses of the relationships between pigments and environmental variables were performed using Time Series Processor version 4.1 (Quantitative Software, USA). AR (1) models were fitted to data sets where serial correlation was a problem, and tests for significant correlations between data series were performed between the series of the residuals (Hall \& Lilien 1986).

\section{RESULTS}

\section{Comparison of HPLC and spectrophotometric methods}

Daily chlorophyll a concentrations calculated from the same sample analysed by HPLC, Jeffrey \& Humphrey (1975) and the Lorenzen (1967) methods are shown in Figs. 2 \& 3 . All 3 methods of estimating chlorophyll concentrations generally indicated the
Fig. 2. Comparison of summer chlorophyll a concentrations ( $\mu \mathrm{g}^{-1}$ ) in the kelp bed, determined by HPLC $(\bullet-)$ and spectrophotometrically by the equations of Jeffery \& Humphrey (1975) (०--) and Lorenzen (1967) $(\Delta \cdots \cdots \Delta)$

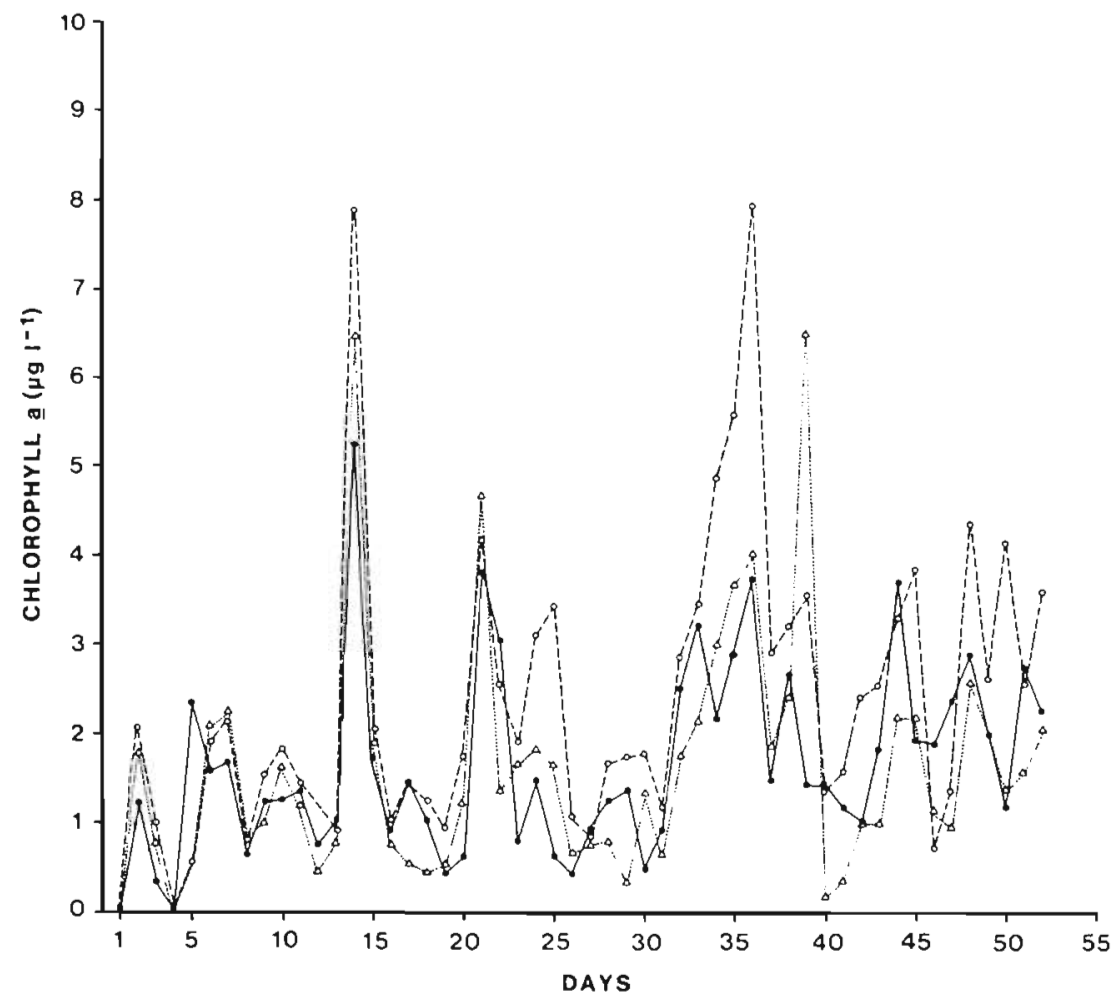




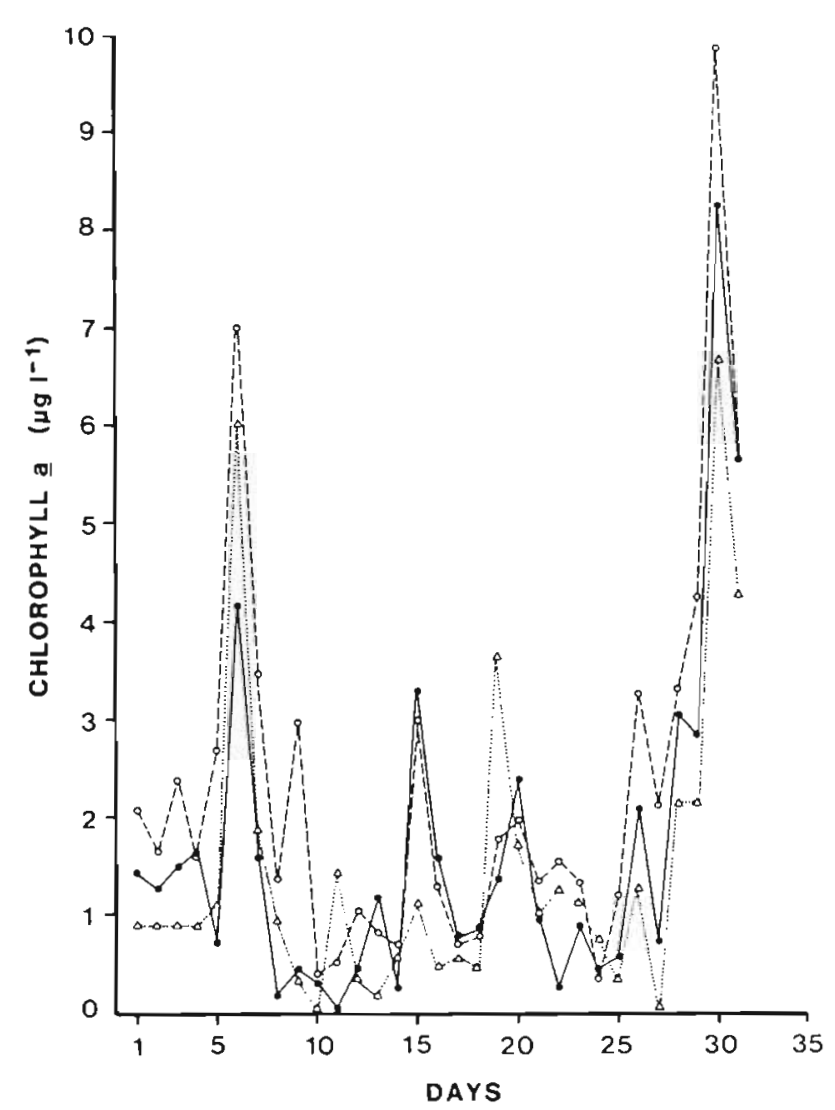

Fig. 3. Comparison of winter chlorophyll a concentrations ( $\mu \mathrm{g}^{-1}$ ) in the kelp bed, determined by HPLC $\longrightarrow \rightarrow$ ) and spectrophotometrically by the equations of Jeffrey \& Humphrey (1975) (c--) and Lorenzen (1967) (A........

same trends, major increases and decreases in chlorophyll a coinciding closely during both summer and winter. Chlorophyll a concentrations calculated using the Jeffrey \& Humphrey (1975) trichromatic equations were generally higher than HPLC estimations, and the 2 methods provided significantly different estimates (paired $t$-test, $\mathrm{p}<0.001, \mathrm{n}=83$ ). However, differences were relatively small. The relationship between HPLC and Jeffrey \& Humphrey (1975) trichromatic values for chlorophyll a extracted in $90 \%$ acetone was $Y=0.51+1.12 X(\mathrm{r}=0.82, \mathrm{n}=83)$ where $Y$ is chlorophyll a concentration in $\mu \mathrm{g} \mathrm{l}^{-1}$ estimated by the equations of Jeffrey \& Humphrey (1975) and $X$ is the chlorophyll a concentration in $\mu \mathrm{g} \mathrm{l}^{-1}$ measured by HPLC. No significant difference between the Lorenzen (1967) and HPLC estimates of chlorophyll a concentrations was found (paired t-test, $p>0.05, n=83$ ).

Mean summer and winter chlorophyll a concentrations estimated by the 3 methods are shown in Table 1. There were no significant differences between pairs of summer and winter values ( $t$-test, $\mathrm{p}>0.01, \mathrm{n}=52$ in summer and $n=31$ in winter).

\section{Chlorophyll $a$ and the environment}

Environmental conditions prevailing during the time series, together with chlorophyll a concentrations determined by HPLC, are shown in Figs. 4 \& 5. Changes in nitrate concentrations in the system during the time series have been described by Muir (1986) and the data on nitrate concentrations are from his work. In summer, pulses of strong southeasterly winds lasting ca 5 d caused upwelling of cold, nitrate-rich water into the kelp bed system and the chlorophyll a concentration in the inshore waters was low (ca $1 \mu \mathrm{g} \mathrm{l}^{-1}$. Fig. 4A, B, $D, E)$. However, when southeasterly winds relaxed or changed to northwesterly, phytoplankton growth in waters with a high nitrate content was rapid and chlorophyll a concentrations increased quickly (Fig. 4A, D, E).

In winter the wind generally blew from the northwest and sea temperatures remained stable (Fig. 5A, B). It is evident from Fig. 5E that the pattern of fluctuations in winter chlorophyll a concentrations in the water was similar to that occurring in summer (Fig. 4E). Chlorophyll a levels were generally low (ca $1 \mu \mathrm{g} \mathrm{I}^{-1}$ ) during northwesterly gales and when the northwesterly winds relaxed, rapid increases in both nitrates and chlorophyll a occurred (Fig. 5A, D, E).

\section{Time series analysis}

In summer, sea temperature and swell height were negatively correlated with the upwelling index of the previous day $(\mathrm{r}=-0.442, \mathrm{p}<0.002$ and $\mathrm{r}=-0.361$, $\mathrm{p}<0.01$ respectively, $\mathrm{df}=49$ ). Summer sea temperatures were also positively correlated with the swell height of $2 \mathrm{~d}$ previously $(\mathrm{r}=0.318, \mathrm{p}<0.05$, df $=49$ ). while winter sea temperatures were negatively correlated with swell height over a similar lag period ( $\mathrm{r}=$ $-0.406, \mathrm{p}<0.05$, df $=28$ ).

Summer chlorophyll a concentrations determined by HPLC were positively correlated with the upwelling index of 5 d previously $(\mathrm{r}=0.295, \mathrm{p}<0.05$, $\mathrm{df}=49$ ), swell height of the same day $(\mathrm{r}=0.343, \mathrm{p}<0.02$,

Table 1. Mean chlorophyll a concentrations ( \pm SD) in the kelp bed water column during summer and winter, estimated by 3 different methods

\begin{tabular}{|lcc|}
\hline Method & $\begin{array}{c}\text { Summer } \\
\text { chlorophyll a } \\
\left(\mu \mathrm{I}^{-1}\right)\end{array}$ & $\begin{array}{c}\text { Winter } \\
\text { chlorophyll a } \\
\left(\mu \mathrm{g} \mathrm{I}^{-1}\right)\end{array}$ \\
\hline HPLC & $1.64( \pm 1.06)$ & $1.78( \pm 1.90)$ \\
Jeffrey \& Humphrey (1975) & $2.37( \pm 2.82)$ & $2.31( \pm 2.05)$ \\
Lorenzen (1967) & $1.63( \pm 1.92)$ & $1.47( \pm 1.61)$ \\
\hline
\end{tabular}




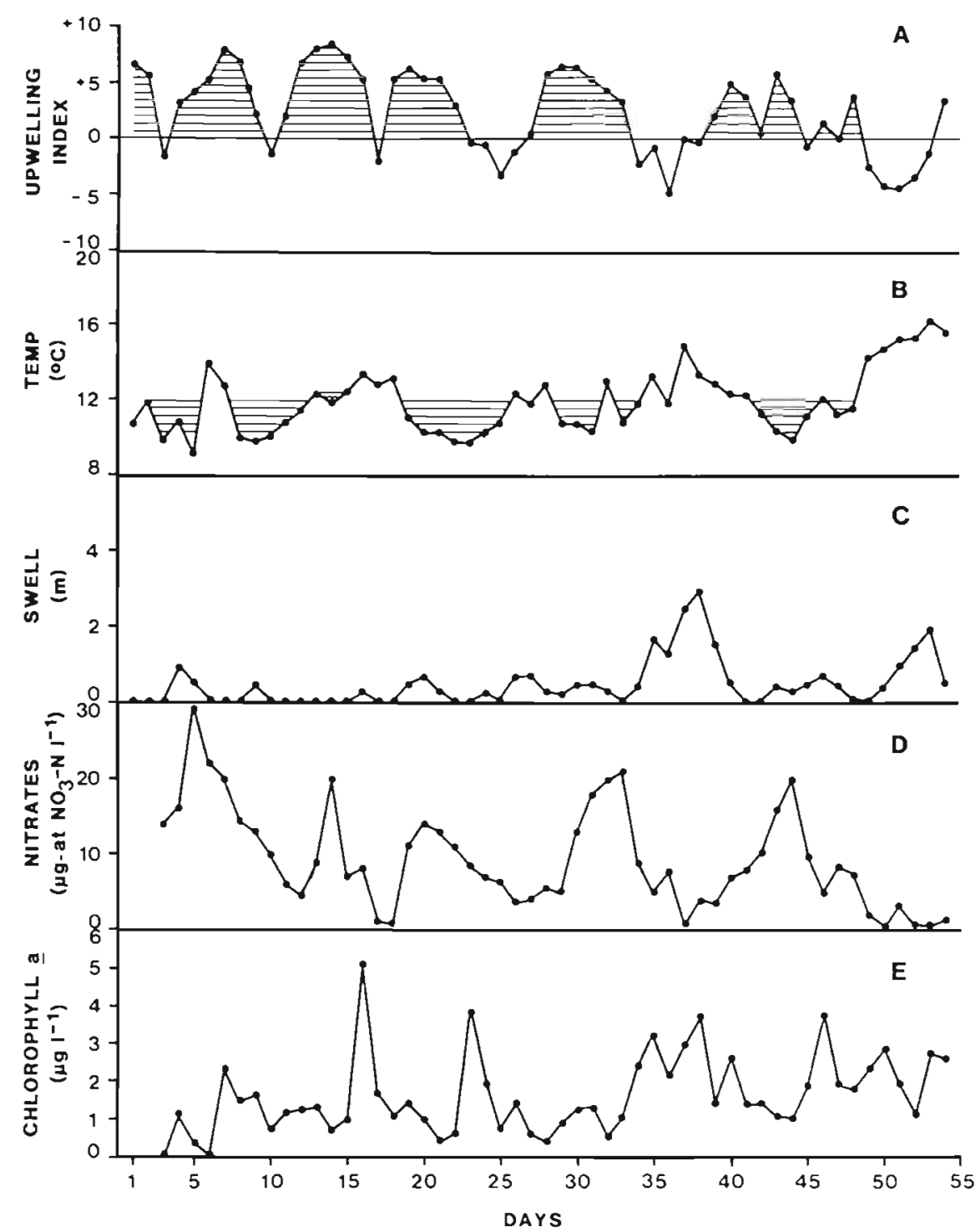

Fig. 4. Variations in physical factors, nitrate and HPLC chlorophyll a concentrations in the kelp bed at Oudekraal during summer. Nitrate concentrations are from Muir (1986). Hatched areas indicate periods of southeasterly winds which cause upwelling of cold water

$\mathrm{df}=49)$ and the sea temperature of the previous day $(r=0.287, p<0.05, \mathrm{df}=49)$. Winter chlorophyll a concentrations were negatively correlated with swell height 2 d previously ( $\mathrm{r}=-0.390, \mathrm{p}<0.005$, df $=29$ ).

\section{Other pigments in particulate material}

Phaeopigments and phaeophytin. Figs. $6 \mathrm{~B} \& 7 \mathrm{~B}$ show respectively daily summer and winter phaeopigment estimates by the Lorenzen (1967) method, and phaeophytin a estimates made by HPLC from the same samples. Phaeophorbide a occurred in $15 \%$ of summer and $21 \%$ of winter samples and peak areas were very small and are thus not included in HPLC phaeopig- ments. Mean summer and winter concentrations determined by the 2 methods are shown in Table 2 . There was a significant difference between phaeopigment concentrations determined by the Lorenzen (1967) method and phaeophytin a concentrations determined by HPLC (paired $t$-test, $p<0.001$ ). The Lorenzen (1967) method indicated persistent phaeopigments in the water column, both in summer and winter, reaching concentrations of $7.04 \mathrm{\mu g} \mathrm{l}^{-1}$. Analysis by HPLC indicated that there were considerable periods when no phaeophytins were present and on only 2 occasions did concentrations exceed $2 \mu \mathrm{g} \mathrm{l}^{-1}$ (Figs. 6B \& 7B). Phaeophytin $a$ and chlorophyll a concentrations of the same day were correlated in winter $(\mathrm{r}=0.494, \mathrm{p}<0.01, \mathrm{df}=28)$.

Chlorophyllide a. Figs. $6 \mathrm{C} \& 7 \mathrm{C}$ show the presence 


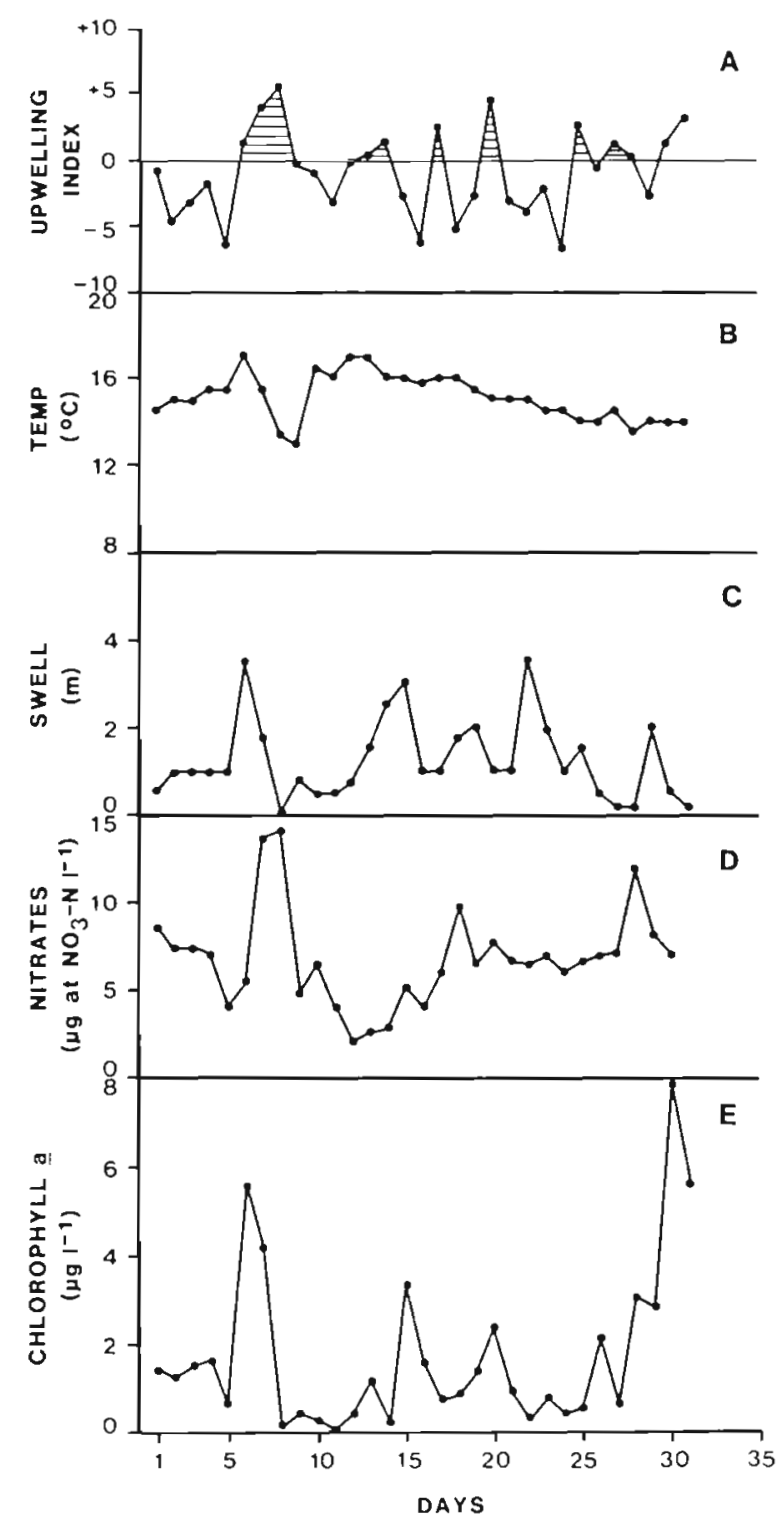

Fig. 5. Variations in physical factors, nitrate and HPLC chlorophyll a concentrations in the kelp bed at Oudekraal during winter. Nitrate concentrations are from Muir (1986).

Hatched areas indicate periods of southeasterly winds

of chlorophyllide a during the time series. Mean summer and winter concentrations of chlorophyllide a were higher than those of phaeophytin a (Table 2) and chlorophyllide a occurred in $57 \%$ of summer samples and $43 \%$ of winter samples, while phaeophytin a occurred in $24 \%$ of summer and $21 \%$ of winter samples. Thus it appears that chlorophyllide a was more

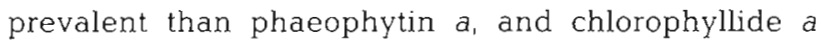
was often present when phaeophytin a was absent (Figs. 6B, C \& 7B, C). Increases in chlorophyllide a concentrations often occurred with or shortly after peaks in chlorophyll a (Fig. 6A, C) and chlorophyllide $a$ and chlorophyll a concentrations of the same day were significantly positively correlated in both summer and winter $(\mathrm{r}=0.343, \mathrm{p}<0.02, \mathrm{df}=49$ and $\mathrm{r}=0.373$, $p<0.05$, df $=28$ respectively) .

Fucoxanthin. Daily fucoxanthin concentrations in the water column during summer and winter are shown in Figs. $6 \mathrm{D} \& \mathrm{DD}$ and mean summer and winter concentrations are shown in Table 2. Fucoxanthin occurred in $91 \%$ of winter samples and $30 \%$ of summer samples. Winter concentrations reached $5.35 \mu \mathrm{g} \mathrm{l}^{-1}$ while the highest concentration recorded in summer was $2.04 \mu \mathrm{g}$ $1^{-1}$. Fig. 7A, D also shows that in winter, fucoxanthin maxima occurred at the same time as chlorophyll a maxima, and fucoxanthin and chlorophyll a concentrations of the same day were highly correlated $(\mathrm{r}=$ $0.718, \mathrm{p}<0.001, \mathrm{df}=28$ ). In summer the 2 pigments were not significantly correlated $(p>0.05)$, and except for the last $9 \mathrm{~d}$ of the sampling period, fucoxanthin maxima occurred at different times to chlorophyll maxima (Fig. 6A, D).

Minor pigments. The presence of minor pigments in the water column in summer and winter is shown in Table 3. Chlorophyll c occurred in $93 \%$ of winter samples and $33 \%$ of summer samples while chlorophyll $b$ occurred more commonly in summer than in winter. Lutein was not a major pigment in the particulate fraction.

\section{DISCUSSION}

It has been shown previously that spectrophotometric methods of estimating chlorophyll a in highly productive lakes and the estuarine benthos may overestimate chlorophyll a concentrations by factors of between 2 and 12.6 when compared with HPLC estimates (Jacobsen 1978, 1982, Mantoura \& Llewyllyn 1983, Daemen 1986). However, there was fairly good correlation between spectrophotometric and HPLC results when samples were taken from the open sea (Mantoura \& Llewellyn 1983, Murray et al. 1986). In the nearshore environment at Oudekraal, estimations of chlorophyll a concentrations determined by the 3 methods did not differ greatly (Figs. $2 \& 3$ ).

The discrepancy between trichromatic and HPLC estimations of chlorophyll a will be greatest when there is a build-up of pigment breakdown products such as chlorophyllides and phaeophorbides. Chlorophyllase activity is particularly vigorous in diatoms (Barret \& Jeffrey 1964). The reduced presence of fucoxanthin and chlorophyll $c$ in the summer phytoplankton population (see 'Fucoxanthin' below) indicated that diatoms were not well represented in the summer phytoplankton blooms. Their absence together with the associated chlorophyllase activity would contribute to reducing 
Fig. 6. HPLC estimates of different algal pigment concentrations in the kelp bed water column during summer. Phaeopigment concentrations determined by the method of Lorenzen (1967) are also shown $(---\infty)$

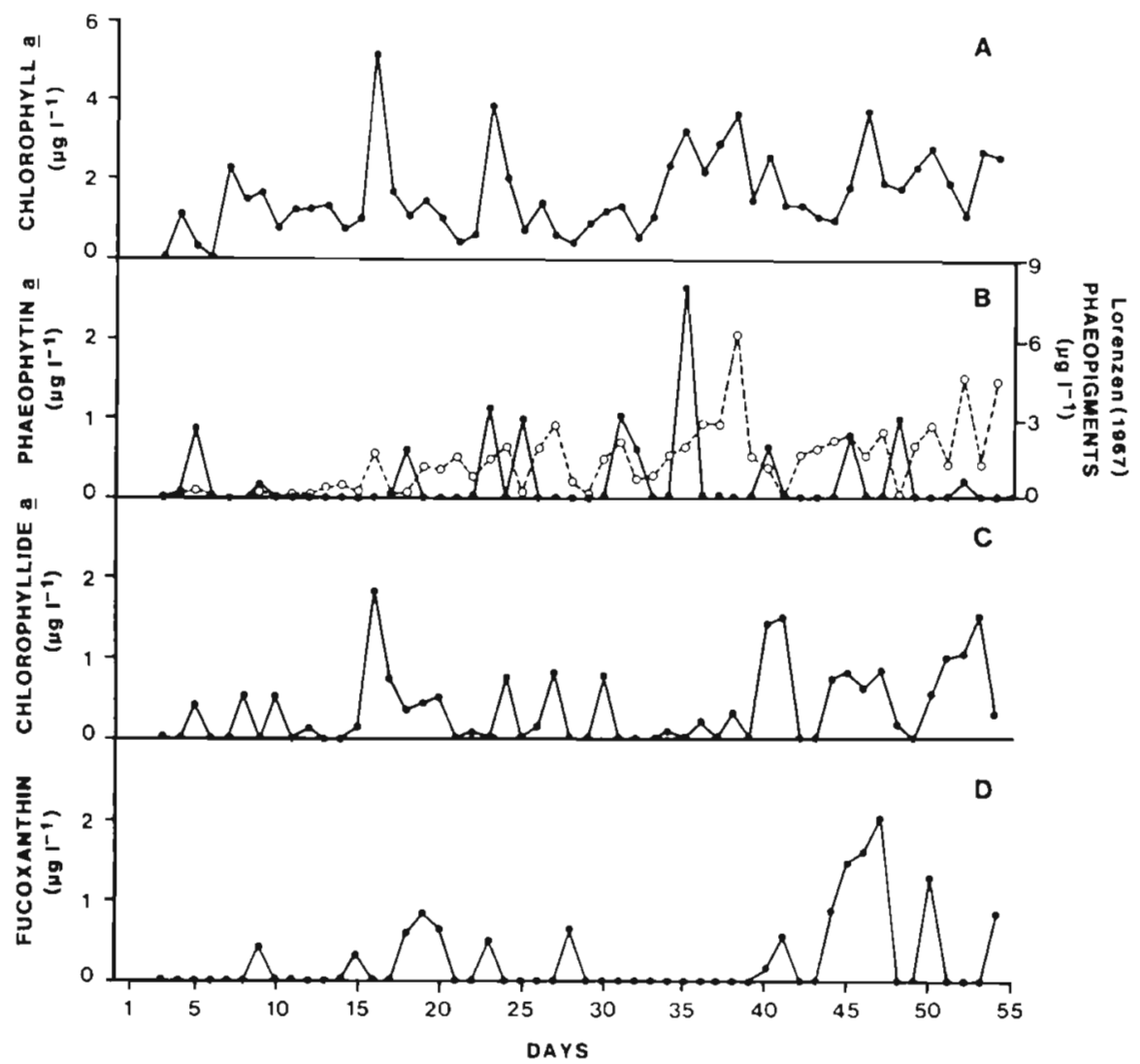

Table 2. Mean auxiliary pigment concentrations $( \pm S D)$ in the kelp bed water column during summer and winter

\begin{tabular}{|lcc|}
\hline Pigment & $\begin{array}{c}\text { Summer } \\
\text { concentration } \\
\left(\mu g \mathrm{I}^{-1}\right)\end{array}$ & $\begin{array}{c}\text { Winter } \\
\text { concentration } \\
\left(\mu g \mathrm{I}^{-1}\right)\end{array}$ \\
\hline Phaeophytin a & $0.21( \pm 0.49)$ & $0.27( \pm 0.74)$ \\
Lorenzen phaeopigments & $1.44( \pm 1.37)$ & $1.67( \pm 1.75)$ \\
Chlorophyllide $a$ & $0.39( \pm 0.49)$ & $0.47( \pm 0.93)$ \\
Fucoxanthin & $0.25( \pm 0.49)$ & $1.34( \pm 1.16)$ \\
\hline
\end{tabular}

Table 3. Percentage of sampling days that various minor pigments occurred in particulate material filtered from the kelp bed water column in summer and winter

\begin{tabular}{|lcc|}
\hline Pigment & Summer & Winter \\
\hline Chlorophyll $b$ & $40 \%$ & $29 \%$ \\
Chlorophyll $c$ & $33 \%$ & $93 \%$ \\
Lutein & $20 \%$ & $39 \%$ \\
Phaeophorbide $a$ & $15 \%$ & $21 \%$ \\
\hline
\end{tabular}

the discrepancy between the 2 methods. Moreover, because of the wind regime, there is considerable movement of water into and out of the kelp bed system (Field et al. 1980). Thus, although phytoplankton blooms occurred at regular intervals (Figs. 2 \& 3), the phytoplankton together with their associated chlorophyll precursors and degradation products may remain in the system for only a brief time, thus reducing any build-up of degradation products.

\section{Comparisons of previous estimates of kelp bed chlorophyll a with HPLC estimates}

The chlorophyll a concentrations recorded using HPLC are similar to summer values of 0 to $10 \mu \mathrm{g}^{-1}$ recorded by Field et al. (1980) in the kelp bed area, using the SCOR-UNESCO (1966) trichromatic equations. Using the same methods, Brown (1984) and Brown \& Field (1985) described values ranging from 0 to $2.5 \mu \mathrm{g} \mathrm{chl} \mathrm{a} \mathrm{l}^{-1}$ in newly upwelled water and 0.8 to $18.2 \mu \mathrm{g} \mathrm{chl} \mathrm{a} \mathrm{l}^{-1}$ in mature upwelled water in the Oudekraal kelp bed. Barlow (1982) recorded values of up to $27.7 \mu \mathrm{g}$ chl a $\mathrm{l}^{-1}$ in aged upwelled water but values for mature and newly upwelled water, though slightly higher, are comparable to those recorded by HPLC. Thus it would appear that previous spectrophotometric estimates of kelp bed chlorophyll a concentrations are similar to those determined by HPLC. This is probably a result of the dynamic nature of the kelp bed system which ensures regular nutrient replacement for an actively growing phytoplankton 


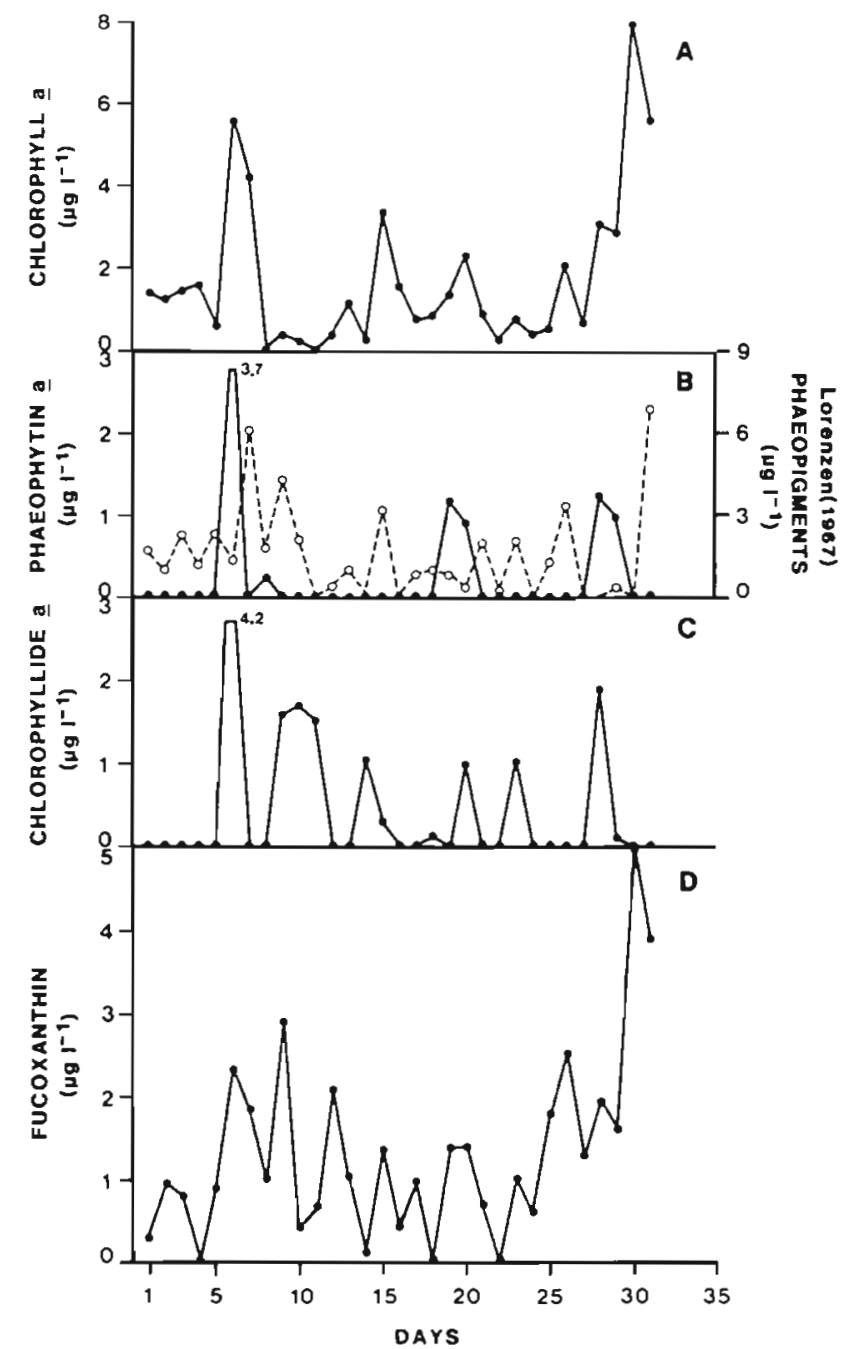

Fig. 7. HPLC estimates of different algal pigment concentrations in the kelp bed water column during winter. Phaeopigment concentrations determined by the method of Lorenzen (1967) are also shown (o---)

population, and allows little time for chlorophyll degradation products to accumulate.

\section{Chlorophyll $a$ and the environment}

The cyclical summer pattern of periods of southeasterly winds resulting in upwelling of cold nitraterich water followed by rapid phytoplankton growth (Fig. 4) has been demonstrated before (Andrews \& Hutchings 1980, Field et al. 1980, Brown 1981, Carter 1982, Brown 1984, Brown \& Field 1986), although there has been no proper time series analysis of the physical and biological events occurring in a typical west coast kelp bed. Time series analysis showed that upwelling occurred rapidly after the onset of southeasterly winds, a reduction in sea temperature lagging the positive longshore wind component by $1 \mathrm{~d}$. The southeasterly winds also appeared to significantly reduce the swell height after a day. It is of interest that chlorophyll a concentrations were positively correlated with the upwelling index of $5 \mathrm{~d}$ previously. Fig. 4 shows that pulses of southeasterly winds lasted ca $5 \mathrm{~d}$ (see also Andrews \& Hutchings 1980, Field et al. 1980) during which time phytoplankton is continually removed from the kelp bed by offshore water movement. Chlorophyll a peaks would therefore coincide with the relaxation of the upwelling cycle. Daily summer chlorophyll a concentrations were also positively influenced by swell height, probably because of increased nutrient mixing, and the resuspension of settled phytoplankton by larger waves. The positive correlation between chlorophyll $\boldsymbol{a}$ and the sea temperature of the previous day may be a reflection of more rapid phytoplankton growth taking place at elevated temperatures.

During winter, swell height appeared to be the dominant environmental factor, large waves being negatively correlated with both sea temperatures and chlorophyll concentrations $2 \mathrm{~d}$ later. Temperature might be lowered by increased mixing with colder bottom waters during periods of larger waves but it is not clear why this effect would take $2 \mathrm{~d}$ to appear. The large winter swells (Fig. 5C) disturb bottom sediments and fragment the kelp fronds, thereby greatly increasing turbidity. The reduction in chlorophyll a concentrations after $2 \mathrm{~d}$ may well be the result of phytoplankton senescence induced by reduced light penetration.

Wulff \& Field (1983) modelled the kelp bed system and predicted that under continuous downwelling, phytoplankton would form $93 \%$ of the particulate matter in the kelp bed. When strong onshore northwesterly winds blow, downwelling is continuous. However, Fig. $5 \mathrm{~A}, \mathrm{E}$ shows that chlorophyll a concentrations in the water were low (ca $1 \mu \mathrm{gl}^{-1}$ ) during these periods, while particulate carbon levels were fairly constant (Fielding \& Davis 1989). It is therefore unlikely that phytoplankton forms as much as $93 \%$ of the particulate load during constant downwelling, and macroalgal particulates and resuspended detritus probably comprise a considerable proportion of the carbon source.

\section{Other pigments in particulate material}

Phaeopigments. Clearly there was a large discrepancy in phaeopigment concentrations measured by the Lorenzen (1967) acidification method and phaeopigments measured by HPLC (Table 2, Figs. 6B \& 7B). Fluorometric determinations of phaeopigments by acidification provided overestimates when compared with HPLC estimates, particularly when chlorophyll $b$ was present (Loftus \& Carpenter 1971). Conventional 
spectrophotometric estimates of bulk phaeopigments (Lorenzen 1967) appear also to be overestimates. This can be partly explained by the presence of chlorophyll $b$ in some of the samples (Holm-Hansen 1978).

Phaeopigment concentrations in marine waters have been used to assess the impact of zooplankton grazing on phytoplankton populations (Daley et al. 1973, Jeffrey 1974, Shuman \& Lorenzen 1975, Boyd et al. 1980, Dagg \& Wyman 1983, Gieskes \& Kraay 1986b). In the kelp bed system, phaeophorbide occurred infrequently (Table 3) and phaeophytin a concentrations were low (Table 2, Figs. 6B \& 7B). This would seem to indicate a low level of zooplankton grazing on the phytoplankton present in the system. However, along the Cape west coast, high zooplankton concentrations are consistently present close to the coast. Strong upwelling may result in temporarily low numbers but recolonization of upwelled water is relatively rapid and zooplankton grazing can account for 13 to $30 \%$ of daily potential phytoplankton production (Hutchings 1988). Significant phaeopigment levels would therefore be expected in the inshore waters. Water movement in and out of the kelp bed system (Field et al. 1980) would preclude any chlorophyll decomposition product build-up, resulting in low phaeopigment values. In addition, phaeopigments may be rapidly photo-oxidised to colourless products in the strong light conditions of the Cape kelp beds (SooHoo \& Kiefer 1982a, b). It has also recently been shown that phaeopigments may not provide an index of grazing pressure, or at best may provide an index of only macrozooplankton grazing. Microzooplankton, which may form an important component of marine food webs, can degrade chlorophyll and carotenoid pigments to colourless residues (Klein et al. 1986, Burkill et al. 1987, Barlow et al. 1988).

Chlorophyllide a. Since chlorophyll $a$ and chlorophyllide a have identical absorption spectra and are thus indistinguishable spectrophotometrically, this has important implications when algal biomass is assessed by this method, particularly where there are high concentrations of diatoms (Barret \& Jeffrey 1964) or in places such as estuarine sediments where chlorophyll decomposition products may accumulate. Chlorophyllide a may be an indicator of senescent phytoplankton populations (Jensen \& Sakshaug 1973, Jeffrey 1974. Hallegraeff 1981), or copepod feeding (Gieskes \& Kraay 1986b). However, at present it is probably unwise to infer too much from chlorophyllide a concentrations since chlorophyllase, which hydrolyses chlorophyll $a$ to chlorophyllide $a$, can be activated by phytoplankton harvesting techniques such as filtration, and this effect is more pronounced where diatom concentrations are high (Suzuki \& Fujita 1986, Jeffrey \& Hallegraeff 1987). In the dynamic kelp bed situation chlorophyllide a levels were generally fairly low (Table
2, Figs. 6C \& 7C) and HPLC and spectrophotometric chlorophyll a determinations did not differ greatly. However, in view of the filtration process employed during the sampling process, it is possible that chlorophyllide a concentrations shown in Figs. 6C \& $7 \mathrm{C}$ are higher than those actually present in the water column. It is of interest that chlorophyllide $a$ and chlorophyll a concentrations of the same day were significantly correlated in both summer and winter and that chlorophyllide a concentrations were somewhat higher in winter when diatoms were more prevalent, than in summer. This may be an indication of chlorophyllase hydrolysis of chlorophyll $a$, activated by the filtration process.

Fucoxanthin. Fucoxanthin is a pigment characteristic of the Bacillariophyta and Phaeophyta (Morris 1971. Parsons et al. 1984). This pigment was much more common in winter than in summer (Figs. 6D \& 7D) and the mean winter concentration was considerably higher than that of summer (Table 2). In addition, daily fucoxanthin and chlorophyll a concentrations were highly correlated in winter but not in summer. Kelp fragmented by large winter waves undoubtedly is a component of the particulate material at this time, but the differences in both the occurrence and concentrations of fucoxanthin in summer and winter suggest that during the sampling period, even during blooms resulting from upwelling, summer phytoplankton populations were frequently not dominated by diatoms. Chlorophyll $c$, also characteristic of the Bacillariophyta and Phaeophyta, was also very much more common in winter than in summer samples, while the reverse was true for chlorophyll $b$ found in the Chlorophyta, Prasinophyta and Euglenophyta (Table 3). The reduced wave action in summer (Fig. 4C) would not have favoured fragmentation of the understorey green macrophytes, and the chlorophyll $b$ was therefore probably from the phytoplankton component of the particulate material. This provides strong evidence that the winter particulate resource was comprised mainly of diatoms and brown algal particles, and was qualitatively different from the summer particulate resource.

Phytoplankton blooms following summer upwelling along the Cape west coast have been considered diatom dominated (Field et al. 1980, Barlow 1982 , Oliviera 1983, Brown \& Field 1985). The 52 d of summer sampling in this study included 5 periods of strong upwelling (Fig. 4A, B), yet diatoms appeared to be a major phytoplankton component in winter rather than in summer. Further HPLC analysis of kelp bed particulate material is required to determine the importance of the green algae in phytoplankton blooms. Spectrophotometric measurements used to determine kelp bed chlorophyll concentrations to date (Field et al. 1980. Brown 1984, Brown \& Field 1985) have not examined 
chlorophyll $b$ concentrations. The green algae may form an important component of phytoplankton communities (Gieskes \& Kraay 1983, Klein \& Sournia 1987), particularly as microzooplankton grazers, which form an integral part of the kelp bed food web (Linley \& Newell 1981, Lucas et al. 1987), have been shown to actively select green algae rather than diatoms when grazing (Burkill et al, 1987).

Acknowledgements. The authors thank Pedro Monteiro for valuable assistance with the HPLC analyses, Dr C. L. Davis for help with sampling, and B. Fielding for production of the figures and typing the manuscript. We also thank Dr M. Lucas for critically reading the manuscript. Financial assistance was provided by the Electricity Supply Commission for P.J.F. and through the Benguela Ecology Programme of the South African National Committee for Oceanographic Research for L.J.S

\section{LITERATURE CITED}

Andrews, W. R. H., Hutchings, L. (1980). Upwelling in the southern Benguela current. Prog. Oceanogr. 9: 1-81

Barlow, R. G. (1982). Phytoplankton ecology in the southern Benguela current. I. Biochemical composition. J. exp. mar. Biol. Ecol, 63: 209-227

Barlow, R. G., Burkill, P. H., Mantoura, R. F. C. (1988). Grazing and degradation of algal pigments by marine protozoan Oxyrrhis marina. J. exp. mar Biol. Ecol. 119: 119-121

Barret, J., Jeffrey, S. W (1964). Chlorophyllase and formation of a typical chlorophyllide in marine algae. Plant Physiol. 39: $44-47$

Boyd, C. M., Smith, S. L., Cowles, T. J. (1980). Grazing patterns of copepods in the upwelling system off Peru. Limnol. Oceanogr 25: 583-586

Brown, P. C. (1981). Pelagic phytoplankton, primary production and nutrient supply in the southern Benguela region. Trans. R. Soc. S. Afr. 44: 347-356

Brown, P. C. (1984). Primary production at two contrasting nearshore sites in the Southern Benguela upwelling region, 1977-1979. S. Afr. J. mar. Sci. 2: 205-227

Brown, P. C., Field, J. G. (1985). Diel variation in production rates of natural phytoplankton populations in the southern Benguela upwelling region. Botanica mar. 28: 201-208

Brown, P. C., Field, J. G. (1986). Factors limiting phytoplankton production in a nearshore upwelling area. J. Plankton Res. 8 (1): 55-68

Burkill, P. H., Mantoura, R. F. C., Llewellyn, C. A., Owens, N. J. P. (1987). Microzooplankton grazing and selectivity of phytoplankton in coastal waters. Mar. Biol. 93: 581-590

Carter, R. A. (1982). Phytoplankton biomass and production in a southern Benguela kelp bed system. Mar Ecol. Prog. Ser. 8: 9-14

Daemen, E. A. M. J. (1986). Comparison of methods for the determination of chlorophyll in estuarine sediments. Neth. J. Sea Res. $20(1): 21-28$

Dagg, M. J., Wyman, K. D. (1983). Natural ingestion rates of the copepods Neocalanus plumchrus and $N$. cristatus calculated from gut contents. Mar. Ecol. Prog. Ser 13: 37-46

Daley, F. J., Gray, C. B. J., Brown, S. R. (1973). A quantitative, semi-routine method for determining algal and sedimentary chlorophyll derivatives. J. Fish. Res. Bd Can. 30 (3): 345-356

Field, J. G., Griffiths, C. L., Linley, E. A. (1980). Upwelling in a nearshore marine ecosystem and its biological implications. Estuar. coast. mar. Sci. 11: 133-150

Fielding, P. J., Davis, C. L. (1989). Carbon and nitrogen resources available to kelp bed filter feeders in an upwelling environment. Mar. Ecol. Prog. Ser. 55: 181-189

Gieskes, W. W. C., Kraay, G. W. (1983). Dominance of Cryptophyceae during the phytoplankton spring bloom in the central North Sea detected by HPLC analysis of pigments. Mar. Biol. 75: 179-185

Gieskes, W. W. C., Kraay, G. W (1986a). Floristic and physiological differences between the shallow and the deep nanoplankton community in the euphotic zone of the open tropical Atlantic revealed by HPLC analysis of pigments. Mar. Biol. 91: 567-576

Gieskes, W. W. C., Kraay, G. W. (1986b). Analysis of phytoplankton pigments by HPLC before, during and after mass occurrence of the microflagellate Corymbellus aureus during the spring bloom in the open North Sea in 1983. Mar. Biol. 92: 45-52

Hall, R. E., Lilien, D. M. (1986). Micro TSP users manual. McGraw Hill, New York

Hallegraeff, G. M. (1981). A seasonal study of phytoplankton. pigments and species at a coastal station off Sydney: the importance of diatoms and the nanoplankton. Mar Biol. 61: $107-118$

Holm-Hansen, O. (1978). Chlorophyll a determination: improvements in methodology. Oikos 30: 438-447

Hutchings, L. (1988). Horizontal distribution of mesozooplankton in the southern Benguela current 1969-1974. Invest. Rep. Div. Fish. S. Afr 131: 1-70

Jacobsen, T R. (1978). A quantitative method for the separation of chlorophylls $a$ and $b$ from phytoplankton pigments by high pressure liquid chromatography. Mar. Sci. Comm. 4: $33-47$

Jacobsen, T. R. (1982). Comparison of chlorophyll a measurements by fluorometric, spectrophotometric and high pressure liquid chromatographic methods in aquatic environments Arch. Hydrobiol. Beih. Ergebn. Limnol. 16: 35-4.5

Jeffrey, S. W. (1974). Profiles of photosynthetic pigments in the ocean using thin-layer chromatography. Mar Biol. 26 $101-110$

Jeffrey, S. W., Hallegraeff, G. M. (1987). Chlorophyllase distribution in ten classes of phytoplankton. A problem for chlorophyll analysis. Mar Ecol. Prog. Ser. 35: 293-304

Jeffrey, S. W., Humphrey, G. F. (1975). New spectrophotometric equations for determining chlorophylls $a, b, c_{1}$ and $c_{2}$ in higher plants, algae, and natural phytoplankton. Biochem. Physiol. Pflanz. 167: 191-194

Jensen, A., Sakshaug, E. (1973). Studies on the phytoplankton ecology of the Trondheimsfijord. II. Chloroplast pigments in relation to abundance and physiological state of the phytoplankton. J. exp. mar. Biol. Ecol. 11 137-155

Jury, M. R. (1980). Characteristics of summer wind field and air sea interactions over the Cape Peninsula upwelling regions. M.Sc. thesis, University of Cape Town

Klein, B., Gieskes, W. W. C., Kraay, G. G. (1986). Digestion of chlorophylls and carotenoids by the marine protozoan Oxyrrhis marina studied by HPLC analysis of algal pigments. J. Plankton Res. 8: 827-836

Klein, B., Sournia, A. (1987). A daily study of the diatom spring bloom at Roscoff (France) in 1985. II. Phytoplankton pigment composition studied by HPLC analysis. Mar Ecol. Prog. Ser. 37: 265-275

Linley, E. A. S., Newell, R. C. (1981). Microheterotrophic communities associated with the degradation of kelp debris. Kieler Meeresforsch., Sonderh. 5: 345-355

Loftus, M. E. Carpenter, J. H. (1971). A fluorometric method 
for determining chlorophylls a, b and c. J. mar. Res. 29 319-338

Lorenzen, C. J. (1967). Determination of chlorophyl] and phaeopigments: spectrophotometric equations. Limnol. Oceanogr 12: 243-246

Lucas, M. I., Probyn, T. A., Painting, S. J. (1987). An experimental study of microflagellate bacterivory: further evidence for the importance and complexity of microplanktonic interactions. S. Afr. J. mar Sci. 5: 791-808

Mantoura, R. F. C., Llewellyn, C. A. (1983). The rapid determination of algal chlorophyll and carotenoid pigments and their breakdown products in natural waters by reversephase high-performance liquid chromatography. Analyt Chim. Acta 151: 297-314

Monteiro, P. M. S. (1986). The potential for the use of high performance liquid chromatography in marine research. Trans. R. Soc. S. Afr. 46 (1): 15-26

Monteiro, P. M. S., Bacon, E. J., Orren, M. J. (1986). The South African SIBEX I cruise to Prydz Bay region, 1984: determination of photosynthetic pigments and their breakdown products by high performance liquid chromatography. S. Afr. J. Antarct. Res. 16 (1): 21-24

Morris, I. (1971). An introduction to the algae. Hutchinson and Co., London

Muir, D. G. (1986). Bacterial populations and their activity in the Benguela upwelling system. Ph.D. thesis, University of Cape Town

Murray, A. P., Gibbs, C. F., Longmore, A. R. (1986). Determination of chlorophyll in marine waters. Intercomparison of a rapid HPLC method with full HPLC, spectrophotometric and fluruometric methods. Mar. Chem. 19: 211-217

Newell, R. C., Field, J. G., Griffiths, C. L. (1982). Energy balance and significance of micro-organisms in a kelp bed community. Mar. Ecol. Prog. Ser. 8: 103-113

Olivieri, E. T. (1983). Colonization, adaptations and temporal

This article was submitted to the editor changes in diversity and biomass of a phytoplankton community in upwelled water of the Cape Peninsula, South Africa, in December 1979. S. Afr. J. mar. Sci. 1: 77-109

Parsons, T R., Takahashi, M., Hargrave, B. (1984). Biological oceanographic processes. Pergamon Press, Oxford

Riemann, B. (1978). Carotenoid interferences in the spectrophotometric determination of chlorophyll degradation products from natural populations of phytoplankton. Limnol. Oceanogr 23: 1059-1066

SCOR-UNESCO (SCOR-UNESCO Working group 17) (1966). Determination of photosynthetic pigments. In: Determination of photosynthetic pigments in seawater. UNESCO Monographs on Oceanographic Methodology 1: 9-18

Shumann, F. R., Lorenzen, C. J. (1975). Quantitative degradation of chlorophyll by a marine herbivore. Limnol. Oceanogr. 20: 580-586

SooHoo, J. B., Kiefer, D. A. (1982a). Vertical distribution of phaeopigments. I. A simple grazing and photooxidative scheme for small particles. Deep Sea Res. 29: 1539-1551

SooHoo, J. B., Kiefer, D. A. (1982b). Vertical distribution of phaeopigments. II. Rates of production and kinetics of photooxidation. Deep Sea Res. 29: 1553-1563

Strickland, J. D. H., Parsons, T R. (1972). A practical handbook of sea water analysis, 2nd edn. Bull. Fish. Res. Bd Can. 167

Suzuki, R., Fujita, Y (1986). Chlorophyll decomposition in Skeletonema costatum: a problem in chlorophyl determination of water samples. Mar. Ecol. Prog. Ser 28: 81-85

Wright, S. W., Jeffrey, S. W. (1987). Fucoxanthin pigment markers of marine phytoplankton analysed by HPLC and HPTLC. Mar. Ecol, Prog. Ser. 38: 259-266

Wulff, F. V., Field, J. G. (1983). Importance of different trophic pathways in a nearshore benthic community under upwelling and downwelling conditions. Mar. Ecol. Prog. Ser 12: $217-228$

Manuscript first received: December 7,1988 Revised version accepted: February 26, 1991 